\title{
Rigid laws and invasive species management
}

\author{
Francisco J. Oficialdegui (10, ${ }^{1 *}$ Miguel Delibes-Mateos $\mathbb{D}^{*},{ }^{2}$ Andy J. Green (iD, ${ }^{1}$ Marta I. Sánchez (D, ${ }^{3}$ \\ Luz Boyero (10, ${ }^{4,5}$ and Miguel Clavero (iD) ${ }^{1}$ \\ ${ }^{1}$ Estación Biológica de Doñana - CSIC, Avenida Américo Vespucio 26, Sevilla, 41092, Spain \\ ${ }^{2}$ Instituto de Estudios Sociales Avanzados - IESA-CSIC, Campo Santo de los Mártires 7, Córdoba, 14004, Spain \\ ${ }^{3}$ Departamento de Biología Vegetal y Ecología, Facultad de Biología, Universidad de Sevilla, Sevilla, Spain \\ ${ }^{4}$ Facultad de Ciencias y Tecnología, Universidad del País Vasco (UPV/EHU), Leioa, 48940, Spain \\ ${ }^{5}$ IKERBASQUE, Basque Foundation for Science, Bilbao, 48013, Spain
}

\section{Introduction}

Conservation conflicts arise frequently in the management of non-native invasive species (NIS) when such species provide socioeconomic benefits and have negative environmental impacts (van Wilgen \& Richardson 2014). For example, when restrictions on exploitation of NIS are applied in response to demands from the public or agencies, NIS users may believe conservation interests take precedence over their interests (Fig. 1). These restrictions are justified by the benefits to biodiversity, but the absence of such benefits may generate a loss of social support for conservation, potentially leading to deregulation. To illustrate, we considered management of the red swamp crayfish in Spain and the European rabbit in New Zealand.

\section{Crayfish Uses, Perceptions, and Regulation}

The North American red swamp crayfish (RSC) (Procambarus clarkii) has been introduced worldwide (Oficialdegui et al. 2020), causing severe impacts on aquatic species and ecosystems (Geiger et al. 2005; Souty-Grosset et al. 2016). The species was introduced to Spain in the 1970 s for commercial purposes and spread rapidly across the Iberian Peninsula (GutiérrezYurrita et al. 1999). It is a key economic resource in southwestern Spain (4,000 t of RSC processed annually, 150,000-200,000 work days, gross income of $\sim € 20$ million) (Conde \& Domínguez 2015).
In 2007, the Spanish Natural Heritage and Biodiversity Law (42/2007) ordered the creation of the Spanish Catalog of Exotic Invasive Species, which should list NIS that severely threaten native biodiversity or the economy and prohibits their possession, transport, or commercialization. The first version of the catalog issued by the royal-decree law (630/2013) listed the RSC, but this and other exploited NIS were excluded from such prohibitions because of their commercial value. In March 2016 the Spanish Supreme Court voided this exception in response to a lawsuit filed by nongovernmental organizations (NGOs) on the basis that a general law should prevail over a royal decree. This decision prohibited the commercial exploitation of RSC and led to widespread public alarm where the species is exploited, and massive protests occurred elsewhere to show public opposition to the decision and the NGOs that requested it.

Environmental management in Spain is decentralized, so in August 2016 to reverse the ban, the Andalusian government approved a crayfish so-called control plan consistent with an EU Regulation (1143/2014) on use of NIS with socioeconomic benefits. This plan held crayfishers responsible for "population control"; and crayfish were delivered to processing plants for trading. In 2018 the Spanish government modified the 42/2007 Law to balance measures against NIS and their exploitation (7/2018 Law) by including the possibility of delisting a species or limiting restrictions related to social and economic interests. Hence, RSC commercial exploitation is currently legal and ongoing.

The RSC is widespread and abundant in southwestern Spain and in most of the Iberian Peninsula, where

*email: oficialdegui@ebd.csic.es

Article impact statement: Flexible management of exploited invasive species when population control is unfeasible avoids public opposition and legal setbacks.

Paper submitted March 21, 2019; revised manuscript accepted January 1, 2020. 


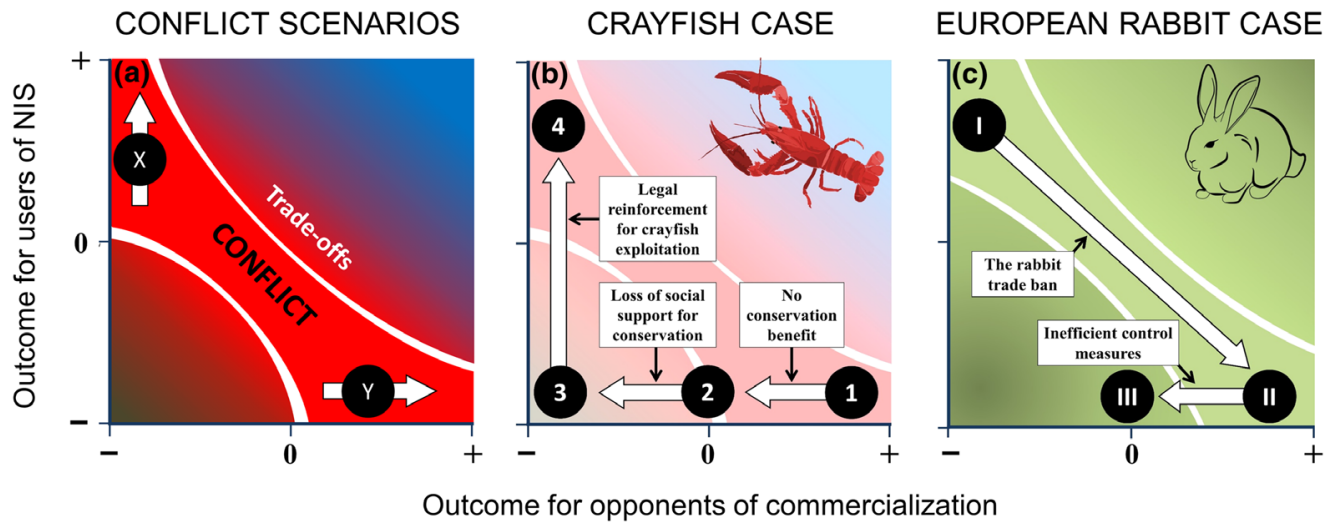

Figure 1. (a) General framework for conflicts arising between non-native invasive species (NIS) users (X) and those who oppose commercial use of NIS (Y) (modified from Redpath et al. [2013]); (b) outcome resulting from regulation of the red swamp crayfish (Procambarus clarkii) in Spain (1, ban crayfish trade; 2, control of crayfish not feasible; 3, economic losses discredit stakebolders against use and degrade societal support of conservation; 4, regulations allow crayfish harvest); and (c) outcomes resulting from historical regulation of the invasive European rabbit (Oryctolagus cuniculus) in New Zealand (I, trade in rabbit meat and fur flourishes but landowner rabbit control inefficient; II, regulations ban commercial use of rabbits; III, unsuccessful rabbit control by agencies).

large-scale population control of the species is not feasible (Gherardi et al. 2011). Although the crayfish industry extracts around 150 million RSC individuals annually, the population has not declined noticeably, and this removal is unlikely to be matched by publicly funded initiatives under a commercial ban. The crayfish ban that was initially intended to favor biodiversity conservation over the crayfish industry failed because of the infeasibility of population control and public protests, particularly among stakeholders, ultimately leading to a general downgrading of NIS management (Fig. 1).

\section{Historical Regulation of European Rabbits in New Zealand}

Native to the Iberian Peninsula, the European rabbit (Oryctolagus cuniculus) has been introduced worldwide (Thompson \& King 1994) and has caused harm in many places (Cooke 2012). It was introduced to New Zealand in the mid-19th century, spread rapidly, and caused severe negative agricultural and environmental impacts. The Rabbit Nuisance Act 1876 required landowners to reduce rabbit numbers. Rabbit meat and fur trade had become a flourishing industry by then ( $>17$ million skins and $>6.5$ million carcasses exported in 1893 and 1900, respectively [Tosh 2005]). Opposition to rabbit commercialization increased among farmers and people concerned about biodiversity conservation, who argued that commercial harvesters were not interested in successful rabbit control because it would be against their economic interests (Cotton \& Hickling 1995). Tensions were evident in local newspapers. The
Otago Daily Times (3 April 1897) called the Rabbit Nuisance Act "infamous" (Tosh 2005). In the 1940s, policy makers increasingly acknowledged that commercial harvesting was not providing effective control, resulting in a shift to a so-called killer policy in 1947 (Godfrey 2014). By 1956, the Rabbit Amendment Act prohibited any trade in rabbit products (Cotton \& Hicking 1995). The rigidity of this and later amendments raised tensions among advocates and detractors of rabbit exploitation (Cotton \& Hicking 1995). Legal instruments and their amendments did not result in effective control of rabbit impacts, whose negative effects on farmlands remain an issue in New Zealand (Norbury \& Reddiex 2005) (Fig. 1). In the 1990s, rabbits became a game species and thus again exploitable (Cotton \& Hicking 1995), but rabbit trade, and subsequent conflicts over exploitation, have almost disappeared.

\section{Pointless Conflicts and Legislative Ways Out}

Conflicts associated with the management of NIS are not always avoidable (Estévez et al. 2015; Crowley et al. 2017). However, if restrictions on the use of NIS result in improvements for the environment, they should be implemented even in the face of opposition. Our case studies show how bans on NIS exploitation generated conflicts without providing evident environmental benefits (Fig. 1). Similar situations will probably occur with management of other NIS, such as the blue crab (Callinectes sapidus), which is causing environmental concern along the Mediterranean coast and whose commercialization recently began (Mancinelli et al. 2017). 
Rigid legal restrictions on NIS exploitation may treat a complex problem as a simple one because they overlook that NIS impacts, and management options to confront them, are context-dependent and change over space and time. Legal instruments regulating the commercial use of NIS need to overcome simplistic approaches (full exploitation or complete ban) and involve more flexible and adaptive strategies because there is no one-size-fitsall solution (Novoa et al. 2015). Although legislative bodies often do not have the capacity to enact a variety of approaches to different NIS, there are some good examples that suggest legal frameworks for management of NIS could be flexible and adaptable to different scenarios in Spain and the EU. For example, legal instruments to manage NIS could define different management options for different invasion scenarios based on a set of features of each NIS (e.g., intensity of impact, time since introduction or geographical spread, plausibility of control and human uses) (Pergl et al. 2016). A good example is the South African Biodiversity Act 2004 and Alien and Invasive Species Lists 2016, where NIS are listed in categories requiring different management actions. Regulatory measures could focus on introduction pathways or specific features that determine the likelihood of NIS becoming established at different stages of invasion (e.g., at the beginning of the invasion process). In the specific case of RSC, banning the possession and transport of live specimens could avoid further spread of the species, and the trade of processed crayfish products could be subjected to more strict controls (e.g., tracing crayfish to catch locations). Therefore, we advocate flexibility in laws for NIS management; several criteria should be considered to establish management strategies appropriate for each group of NIS and at each stage of the invasion process.

The engagement of stakeholders (e.g., scientists, NIS users, and NGOs) in the planning of NIS legislation (Novoa et al. 2018; Shackleton et al. 2019) may minimize future conflicts. However, a consensus among stakeholders is often hindered by the lobbying of the conflicting parties to generate or modify legal instruments, as occurred in New Zealand with rabbits in the mid-20th century and with RSC recently in Spain. A flexible legal framework that considers different management scenarios for NIS, as we described above, could also include collaborative approaches for the implementation of specific management actions. Valuable options include multicriteria evaluation approaches (Liu et al. 2011) and structured decision making (Estévez et al. 2015).

We called attention to the need to avoid rigidity of laws in NIS management to avoid social conflicts that lead to no tangible benefits to biodiversity. In other words, efforts should be made to design more flexible and adaptive regulations for NIS management. Otherwise, advances in NIS management and environmental improvements derived from them may be moot due to the loss of social support.

\section{Acknowledgments}

We thank M. Delibes, A. Rodríguez, C. GutiérrezExpósito, E. Revilla, P. Pons, J. Román, C. Rodríguez, P. González, F. Ribeiro, V. Hermoso, and C. Rouco, who discussed previous versions of the manuscript with us and helped improve it. We also thank 5 anonymous reviewers and 4 editors for their constructive comments and suggestions. FJ.O. was supported by an Andalusian Government grant (project RNM-936).

\section{Literature Cited}

Conde A, Domínguez J. 2015. A proposal for the feasible exploitation of the red swamp crayfish Procambarus clarkii in introduced regions. Conservation Letters 8:440-448.

Cooke BD. 2012. Rabbits: manageable environmental pests or participants in new Australian ecosystems? Wildlife Research 39: 279-289.

Cotton M, Hickling G. 1995. Commercialisation of wild rabbits in New Zealand. In Agriculture \& Economics Conference proceedings. Agribusiness and Economics Research Unit, Canterbury. Available from https://researcharchive.lincoln.ac.nz/handle/10182/964 (accessed February 2020).

Crowley SL, Hinchliffe S, McDonald RA. 2017. Conflict in invasive species management. Frontiers in Ecology and the Environment 15:133-141.

Estévez RA, Anderson CB, Pizarro JC, Burgman MA. 2015. Clarifying values, risk perceptions, and attitudes to resolve or avoid social conflicts in invasive species management. Conservation Biology 29:1930.

Geiger W, Alcorlo P, Baltanas A, Montes C. 2005. Impact of an introduced Crustacean on the trophic webs of Mediterranean wetlands. Biological Invasions 7:49-73.

Gherardi F, Aquiloni L, Diéguez-Uribeondo J, Tricarico E. 2011. Managing invasive crayfish: Is there a hope? Aquatic Sciences 73: 185-200.

Godfrey WU. 2014. Effective rabbit management in a post RHD environment in New Zealand. PhD dissertation. Lincoln University, Canterbury.

Gutiérrez-Yurrita PJ, Martinez JM, Ilhéu M, Bravo-Utrera MA, Bernardo JM, Montes C. 1999. The status of crayfish populations in Spain and Portugal. Crustacean Issues 11:161-192.

Liu S, Sheppard A, Kriticos D, Cook D. 2011. Incorporating uncertainty and social values in managing invasive alien species: a deliberative multi-criteria evaluation approach. Biological Invasions 13:2323.

Mancinelli G, Chainho P, Cilenti L, Falco S, Kapiris K, Katselis G, Ribeiro F. 2017. On the Atlantic blue crab (Callinectes sapidus Rathbun 1896) in southern European coastal waters: Time to turn a threat into a resource? Fisheries Research 194:1-8.

Norbury G, Reddiex B. 2005. European rabbit. Pages 131-150 in CM King, Editor. The handbook of New Zealand mammals. Oxford University Press, Melbourne.

Novoa A, Kaplan H, Kumschick S, Wilson JRU, Richardson DM. 2015. Soft touch or heavy hand? Legislative approaches for preventing invasions: Insights from Cacti in South Africa. Invasive Plant Science and Management 8:307-316.

Novoa A, et al. 2018. A framework for engaging stakeholders on the management of alien species. Journal of environmental management 205:286-297.

Oficialdegui FJ, Sánchez MI, Clavero M. 2020. One century away from home: how the red swamp crayfish took over the world. Reviews in Fish Biology and Fisheries 30:121-135. 
Pergl J, et al. 2016. Black, Grey and Watch Lists of alien species in the Czech Republic based on environmental impacts and management strategy. NeoBiota 28:1-37.

Redpath SM, et al. 2013. Understanding and managing conservation conflicts. Trends in Ecology \& Evolution 28:100109.

Shackleton RT, et al. 2019. Stakeholder engagement in the study and management of invasive alien species. Journal of Environmental Management 229:88-101.

Souty-Grosset C, Anastacio PM, Aquiloni L, Banha F, Choquer J, Chucholl C, Tricarico E. 2016. The red swamp crayfish Procambarus clarkii in Europe: impacts on aquatic ecosystems and human wellbeing. Limnologica 58:78-93.

Thompson HV, King CM. 1994. The European rabbit: the history of a successful colonizer. Oxford University Press, Oxford, United Kingdom.

Tosh EJ. 2005. Furs to furriers in Dunedin, New Zealand, to 1940. MS thesis. University of Otago, Dunedin. Available from http://hdl. handle.net/10523/6806 (accessed August 2019).

van Wilgen BW, Richardson DW. 2014. Challenges and trade-offs in the management of invasive alien trees. Biological Invasions 16:721734. 